\title{
Expression, Purification and Crystallization of Thermostable Mutant of Cutinase Est1 from Thermobifida alba
}

\author{
Kengo Kitadokoro $^{1 *}$, Shingo Matsui ${ }^{1}$, Ryouhei Osokoshi ${ }^{1}$, Kensuke Nakata ${ }^{1}$, Shigeki Kamitani ${ }^{2}$ \\ ${ }^{1}$ Departmentof Biomolecular Engineering, Graduate School of Science and Technology, Kyoto Institute of Technology, \\ Kyoto, Japan \\ ${ }^{2}$ Graduate School of Comprehensive Rehabilitation, College of Health and Human Sciences, Osaka Prefecture University, Osaka, \\ Japan \\ Email: *kengo@kit.ac.jp
}

How to cite this paper: Kitadokoro, K., Matsui, S., Osokoshi, R., Nakata, K. and Kamitani, S. (2018) Expression, Purification and Crystallization of Thermostable Mutant of Cutinase Est1 from Thermobifida alba. Advances in Bioscience and Biotechnology, 9, 215-223.

https://doi.org/10.4236/abb.2018.95015

Received: March 17, 2018

Accepted: May 27, 2018

Published: May 30, 2018

Copyright $\odot 2018$ by authors and Scientific Research Publishing Inc. This work is licensed under the Creative Commons Attribution International License (CC BY 4.0).

http://creativecommons.org/licenses/by/4.0/

\begin{abstract}
A double mutantEst1, which is a plastic degrading cutinase-type esterase in Thermobifida alba, has been over-expressed in Escherichia coli. The recombinant protein was purified by a two-step protocol involving immobilized metal affinity chromatography and cation-exchange chromatography, yielding $120 \mathrm{mg}$ of protein per liter of bacterial culture. Crystals have been obtained by using the sitting-drop vapor-diffusion technique. Native diffraction data to $1.37 \AA$ resolution were obtained at the BL44XU beam line of SPring-8 from a flash-frozen crystal at $100 \mathrm{~K}$. The crystals belong to space group $C 2$, with unit-cell parameters $a=127.2 \AA, b=42.1 \AA, c=63.2 \AA, \beta=114.7^{\circ}$, likely containing one Est1 double mutant (296 residues) per asymmetric unit.
\end{abstract}

\section{Keywords}

Cutinase, Themobifida alba, Plastic Degrading Esterase, Crystallization, High Resolution Crystallographic Data

\section{Introduction}

Plastic degrading enzymes were very important for reducing plastic waste and various cutinases were capable to degrade plastic [1]. The genes for polyester-hydrolyzing enzymes from Thermobifida alba [2], Thermobifida fusca [3], and Thermobifida cellulosilytica [4] have been cloned and determined to encode serine hydrolases that belong to the lipase/esterase family. The genus Thermobifida possesses two tandem cutinase genes in general [5]. Thermobifida alba also produces two cutinases from different genes, est 1 and est119 [6]. Est119, re- 
named cutinase2, was first investigated and characterized as polyester-hydrolyzing type esterase from Thermobifida alba [2]. Lately, it was found that Est1 also has the ability to degrade ester type plastics [5]. The two cutinases from Thermobifida alba showed different activities and thermostabilities, although they share 95\% identity and 98\% similarity. Est 1 showed approximately 2 -fold higher activity than Est119 [5].

We first determined the crystal structure of Est119 as the polyester hydrolyzing type cutinase [7]. Other groups also determined the crystal structures of cutinases from Thermobifida fusca [8] and Thermobifida cellulosilytica [9].

Est1 mutants were constructed for increasing thermostability and enzymatic activity. Interestingly, it was found that Est1 (A68V/T253P) double mutant (Est1DM) had higher enzymatic activity than wild type Est1 and Est119, and was stable for 1 hour below $333 \mathrm{~K}$ and even at $338 \mathrm{~K}$, more than $70 \%$ and $50 \%$ activities were maintained after 30 and $60 \mathrm{~min}$, respectively [6]. It is also reported that Est1DM degraded various aliphatic and aliphatic-co-aromatic polyesters and PET film [6].

We wanted to shed light on the so far undiscovered structural bases of Thermobifida cutinases, and to unveil the relationships between high activities and thermostable differences from comparing cutinase 3D structures of Est1DM with Est119. Toward this goal, we present here the overexpression, purification, crystallization and preliminary X-ray diffraction analysis of the thermostable mutant of cutinase Est1 from Thermobifida alba.

\section{Materials and Methods}

\subsection{Protein Expression and Purification}

Twenty mililiters of an overnight culture of $E$. coli cells Rosetta-gami B (DE3) transformed with pQE80L-est1 was inoculated to $400 \mathrm{~mL}$ of LB medium with 50 $\mu \mathrm{g} \cdot \mathrm{ml}^{-1}$ ampicillin (Table 1 ). Different culture conditions were tested with 10 $\mathrm{mL}$ small scale broth for expression check. The culture broth was grown at $310 \mathrm{~K}$ with vigorous shaking until the $\mathrm{Abs}_{600 \mathrm{~nm}}$ reached 0.6. Then protein expression was induced by the addition of isopropyl-1-thio- $\beta$-D-galactopyranoside (IPTG, Nacalai Japan) to the culture to give a final concentration of $0.1 \mathrm{mM}$. Two types temperature was tested with $310 \mathrm{~K}$ and $298 \mathrm{~K}$, respectively. For the $310 \mathrm{~K}$, both six hours and overnight (18 hours) culture after induction were tested. For $298 \mathrm{~K}$ culture were tested with overnight (18 hours). And then the cells were harvested by centrifugation at $4000 \mathrm{rpm}$ for $30 \mathrm{~min}$ at $277 \mathrm{~K}$, washed with ice-cold deionized distilled water, suspended in lysis buffer $(50 \mathrm{mM}$ Tris- $\mathrm{HCl}$ buffer $\mathrm{pH} 8.0$ including $0.3 \mathrm{M} \mathrm{NaCl}$ and $1 \mathrm{mM}$ imidazole), and then disrupted by sonication with Ultrasonic Disruptor UD-211 (TOMY) at $273 \mathrm{~K}$. The disrupted cell suspension was centrifuged at $8000 \mathrm{rpm}$ for $40 \mathrm{~min}$ at $277 \mathrm{~K}$ to pellet insoluble material. The supernatant was purified by immobilized metal affinity chromatography (HIS-Select Nickel Affinity Gel, Sigma-Aldrich, Germany), which was equilibrated with lysis buffer, the sample was loaded and washed 5 times with lysis 
Table 1. Macromolecule production information.

\begin{tabular}{cc}
\hline Source organism & Thermobifida alba \\
\hline DNA source & Genbank AB445476 \\
Forward primer & 5'-CGCGGATCCAACCCCTACGAACGCGGC-3' \\
Reverse primer & 5'-GCGAAGCTTGAACGGGCAGGTGGAGCGGT-3' \\
Cloning vector & pGEM-T \\
Expression vector & pQE80L-est1 \\
Expression host & E. coli Rosetta-gami (DE3) \\
& MRGSHHHHHHGSNPYERGPNPTESMLEARSGPFSVS \\
& EERVSRLGADGFGGGTIYYPRENNTYGAIAISPGYTG \\
& NQSSIAWLGERIASHGFVVIAIDTNTTLDQPDSRARQL \\
Complete amino & TLRLASQRPDLKAAIPLTPWHLNKSWRDITVPTLIIGA \\
acid sequence of the & DLDTIAPVSSHSEPFYNSIPSSTDKAYLELNNATHFAPN \\
construct produced & IPNKTIGMYSVAWLKRVDEDTRYTQFLCPGPRTGLLS \\
& DVDEYRSTCPF \\
\hline
\end{tabular}

buffer, then the soluble recombinant protein was eluted with an imidazole concentration gradient $(1-500 \mathrm{mM})$ with lysis buffer. The Est1DM fraction was collected and dialyzed to buffer $\mathrm{A}(0.1 \mathrm{M} \mathrm{NaCl} 10 \mathrm{mM}$ Tris- $\mathrm{HCl} \mathrm{pH} \mathrm{8.0)}$ to remove imidazole. Further purification was carried out by MonoS (GE Healthcare, Sweden) column chromatography, which was equilibrated with buffer A, then the dialyzed protein was loaded and washed 5 times with buffer $\mathrm{A}$, then the protein was eluted with a $\mathrm{NaCl}$ concentration gradient $(0-1.0 \mathrm{M})$. The fractions containing the Est1DM protein were combined and dialyzed to $0.2 \mathrm{M} \mathrm{NaCl} 10$ $\mathrm{mM}$ Tris- $\mathrm{HCl} \mathrm{pH}$ 8.0. The Est1DM protein was concentrated to $15 \mathrm{mg} \cdot \mathrm{ml}^{-1}$ by using a VIVASPIN 15 turbo concentrator (Sartorius, Germany) and sterile-filtrated by $0.1 \mu \mathrm{m}$ Ultrafree-MC (Merck Millipore, Germany) device. The homogeneity of the purified preparation was confirmed by $15 \%$ SDS-PAGE and native PAGE.

\section{Determination Specific Activity}

Enzymatic activities were determined by using $p$-nitrophenyl butyrate (pNFB) ester substrates as previously described. For inhibition studies, the concentration of enzyme was adjusted to $0.001 \mathrm{mM}$, inhibitors to $0.2 \mathrm{mM}$, and pNFB to $1 \mathrm{mM}$. Each assay was performed at $37^{\circ} \mathrm{C}$ in $50 \mathrm{mM}$ Tris-HCI pH 8.0 containing $10 \%$ dimethyl-formamide in 1-ml cuvettes. Reactions were started by the addition of substrate after pre-incubation at $37^{\circ} \mathrm{C}$ for $5 \mathrm{~min}$ with various inhibitors. The absorbance of liberated $p$-nitrophenol was monitored continuously at $405 \mathrm{~nm}$ and the initial linear velocity was used to calculate the specific activities of cutinases, which was expressed as an amount $(\mu \mathrm{mol})$ liberated of $p$-nitrophenol using 1.0 $\mathrm{mg}$ cutinase in $1 \mathrm{~min}$ under above conditions.

\subsection{Crystallization}

For crystallization experiments, a $15 \mathrm{mg} \cdot \mathrm{ml}^{-1}$ solution of the recombinant 
Est1DM, in 0.2 M NaCl, $10 \mathrm{mM}$ Tris- $\mathrm{HCl}, \mathrm{pH}$ 8.0, was employed. Crystallization trials were set up at $295 \mathrm{~K}$ as sitting-drop vapor-diffusion experiments on Cryschem $^{\mathrm{TM}}$ crystallization plates. Initial screening was performed using the sparse-matrix method [10] with commercial crystal screening kits (Hampton Research). Several condition optimizations were performed by changing protein concentration, precipitant concentration and $\mathrm{pH}$.

\subsection{Data Collection and Processing}

X-ray diffraction data on Est1DM crystals were collected at $100 \mathrm{~K}$ in a nitrogen stream, supplementing the mother liquor solution with 30\% PEG400 as cryoprotectant. X-ray preliminary data sets were collected from a single crystal on beamline BL44XU at SPring-8. The X-ray wavelength was $0.9 \AA$, the angle oscillation range was $1.0^{\circ}$ and the crystal-to-detector distance was $180 \mathrm{~mm}$. The diffraction images were integrated and scaled using the program packages HKL2000 [11].

\section{Results and Discussion}

Est1DM was expressed in $E$. coli and purified by affinity-resin and cation-exchange chromatography. Different temperature and shaking time of growth conditions were tried several times for obtaining a large number of recombinant protein. The overnight culture at $310 \mathrm{~K}$ gave very few amount of proteins (Table 2), but the six hours culture after induction with IPTG, which was enough even $0.1 \mathrm{mM}$ final concentration, gave a lot of cutinase after immobilized metal affinity chromatography (IMAC) with batch methods (Figure 1(a)). But the overnight culture at $298 \mathrm{~K}$ gave a twice amount of Est1DM than $310 \mathrm{~K}$ with six hours (Table 2). Results of growth conditions and the protein amounts by IMAC batch methods are given in Table 2 . It has been successfully improved to obtain a large amount of purified recombinant Est1DM; the protein yield was more than $120 \mathrm{mg}$ per liter of E. coli culture (Figure 1(b)). This condition is suitable for protein crystallization experiments including crystallization

Table 2. Improving of growth conditions.

\begin{tabular}{cccc}
\hline & Est1-dm & Est1-dm & Est1-dm \\
\hline Culture conditions & $25^{\circ} \mathrm{C} \mathrm{O} / \mathrm{N}$ & $37^{\circ} \mathrm{C} \cdot 6 \mathrm{~h}$ & $37^{\circ} \mathrm{C} \mathrm{O} / \mathrm{N}$ \\
Culture volume $(\mathrm{mL})$ & 10 & 10 & 10 \\
IPTG concentration $(\mathrm{mM})$ & 0.1 & 0.1 & 0.1 \\
Harvested cells $(\mathrm{g})$ & 0.3 & 0.2 & 5 \\
Eluted volume $(\mathrm{mL})$ & 5 & 5 & 0.4 \\
Protein concentration $(\mathrm{mg} / \mathrm{mL})$ & 2 & 1 & 0.6 \\
Total protein $(\mathrm{mg})$ & 10 & 5 & 5
\end{tabular}

Cell were suspended $30 \mathrm{~mL}$ with lysis buffer after loading sample on $\mathrm{Ni}$ column, the columns were washed $12 \mathrm{~mL}$ with lysis buffer. (lysis buffer; $1 \mathrm{mM}$ imidazole $10 \mathrm{mM}$ Tris- $\mathrm{HCl} \mathrm{pH} 8,0.3 \mathrm{M} \mathrm{NaCl}$ ) Then the columns were eluted by batch method with $250 \mathrm{mM}$ imidazole $10 \mathrm{mM}$ Tris- $\mathrm{HCl} \mathrm{pH} 8,0.3 \mathrm{M} \mathrm{NaCl}$. 
Table 3. Crystallization.

\begin{tabular}{cc}
\hline Method & Sitting-drop vapor diffusion \\
\hline Plate type & 24 -well \\
Temperature (K) & 295 \\
Protein concentration $\left(\mathrm{mg} \cdot \mathrm{mL}^{-1}\right)$ & 15 \\
Buffer composition of protein solution & $10 \mathrm{mM}$ Tris-HCl pH8.0, $200 \mathrm{mM} \mathrm{NaCl}$ \\
Composition of reservoir solution & $7 \%$ PEG 4000, 0.2 M Sodium Acetate \\
Volume and ratio of drop & $0.1 \mathrm{M}$ MES pH6.5 \\
Volume of reservoir $(\mathrm{mL})$ & $1: 1$ \\
\end{tabular}

screening. The final purified protein was confirmed by SDS-PAGE as shown in Figure $1(\mathrm{c})$ and the enzymatic activity was also confirmed by using p-nitrophenyl butylate as a hydrolyzing substrate (data not shown).

Crystallization screenings were repeated using various crystallization kits. Crystals of the recombinant Est1DM proteins were readily grown from polyethylene-glycol solutions. The best crystals were obtained through equilibration against a solution containing 5\% - 8\% PEG3350, 0.1 M sodium acetate and $0.1 \mathrm{M}$ MES buffer, pH 6.5, $293 \mathrm{~K}$, in sitting-drop vapor-diffusion setups (Table 3). The crystallization droplets consisted of $1 \mu \mathrm{l}$ protein and $1 \mu \mathrm{l}$ reservoir solutions, with $500 \mu \mathrm{l}$ of reservoir solution, plate like crystals appeared within a few weeks and grew to maximum dimensions of about $1.5 \times 0.2 \times 0.1 \mathrm{~mm}^{3}$ (Figure 2).

$\mathrm{X}$-ray diffraction data were collected at a resolution of $1.37 \AA$ (Figure 3). The crystals belonged to the centered monoclinic space group $C 2$, with unit-cell parameters $a=127.2 \AA, b=42.1 \AA, c=63.2 \AA, \beta=114.7^{\circ}$ (see Table 4). A total of 250,545 reflections in the resolution range $50.0-1.37 \AA$ were collected with 98.3\% completeness and an $R$ merge of $4.7 \%$. The data-collection and processing statistics are summarized in Table 4. Assuming a $\mathrm{M}_{r}$ of $31.7 \mathrm{kDa}$ (296 residues) for the expressed Est1DM domain, packing density calculations indicate the most probable value for $V_{\mathrm{M}}$ as $2.42 \AA^{3} \mathrm{Da}^{-1}$, with one Est1DM chain per asymmetric unit. This corresponds to a solvent fraction of about $49.2 \%$, a typical value for protein crystals [12].

We are currently attempting phase determination by the molecular-replacement method using the crystal structure of Est119 from Thermobifida alba (PDB entry 3VIS) [7] as a search model with the program [13] included in the CCP4 program package [14]. A single correct solution was found and complete structure determination and refinement are in progress.

\section{Acknowledgements}

We are grateful to all members of beamline BL44XU at SPring-8 for their help in collecting data. Use of the synchrotron beamline BL44XU at SPring-8 was obtained through the Cooperative Research Program of the Institute for Protein 


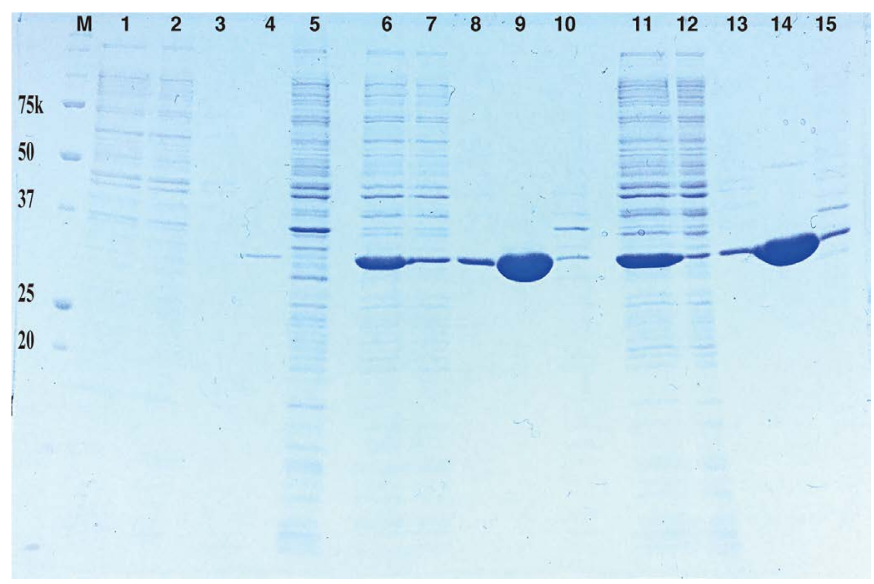

(a)

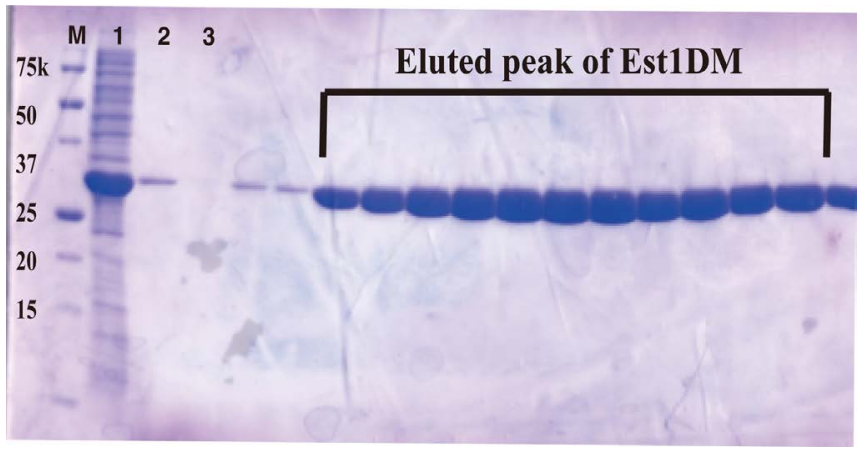

(b)

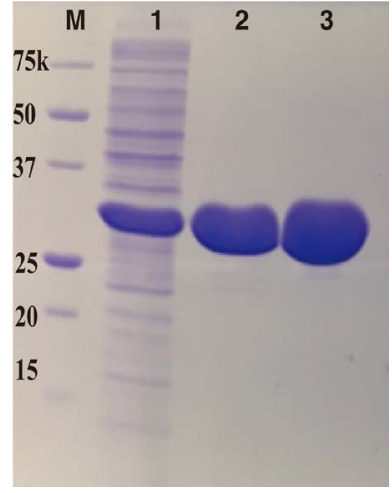

(c)

Figure 1. (a) Small scale expression check. M, corresponds to the molecular weight standards $(\mathrm{kDa})$, lane 1 , cell lysate; lane 2 , flow through; lane 3 , washed elution with lysis buffer; lane 4, Ni chromatography elution; lane 5, cytosol ( $37^{\circ} \mathrm{C}, 18$ hours); lane 6 , cell lysate; lane 7 , flow through; lane 8 , washed elution with lysis buffer; lane 9; Ni chromatography elution; lane 10 , cytosol $\left(37^{\circ} \mathrm{C}, 6\right.$ hours); lane 11, cell lysate; lane 12, flow through; lane 13 , washed elution with lysis buffer; lane $14, \mathrm{Ni}$ chromatography elution; lane 15, cytosol $\left(25^{\circ} \mathrm{C}, 18\right.$ hours); (b) Purification by Mono S chromatography. SDS-PAGE analysis of peak fractions indicates a purity of $>99 \%$ : $\mathrm{M}$, corresponds to the molecular weight standards $(\mathrm{kDa})$, lane 1, cell lysate; lane 2, Flow through, lane 3, washed elution with lysis buffer; lane 4 to the end results of the Mono S column elution. (c) SDS-PAGE gel (15\%) stained with Coomassie Brilliant Blue. $\mathrm{M}$, molecular-weight markers (labelled in $\mathrm{kDa}$ ); lane 1, cell lysate; lane 2, protein after nickel-NTA chromatography; lane 3, the final purified protein. 


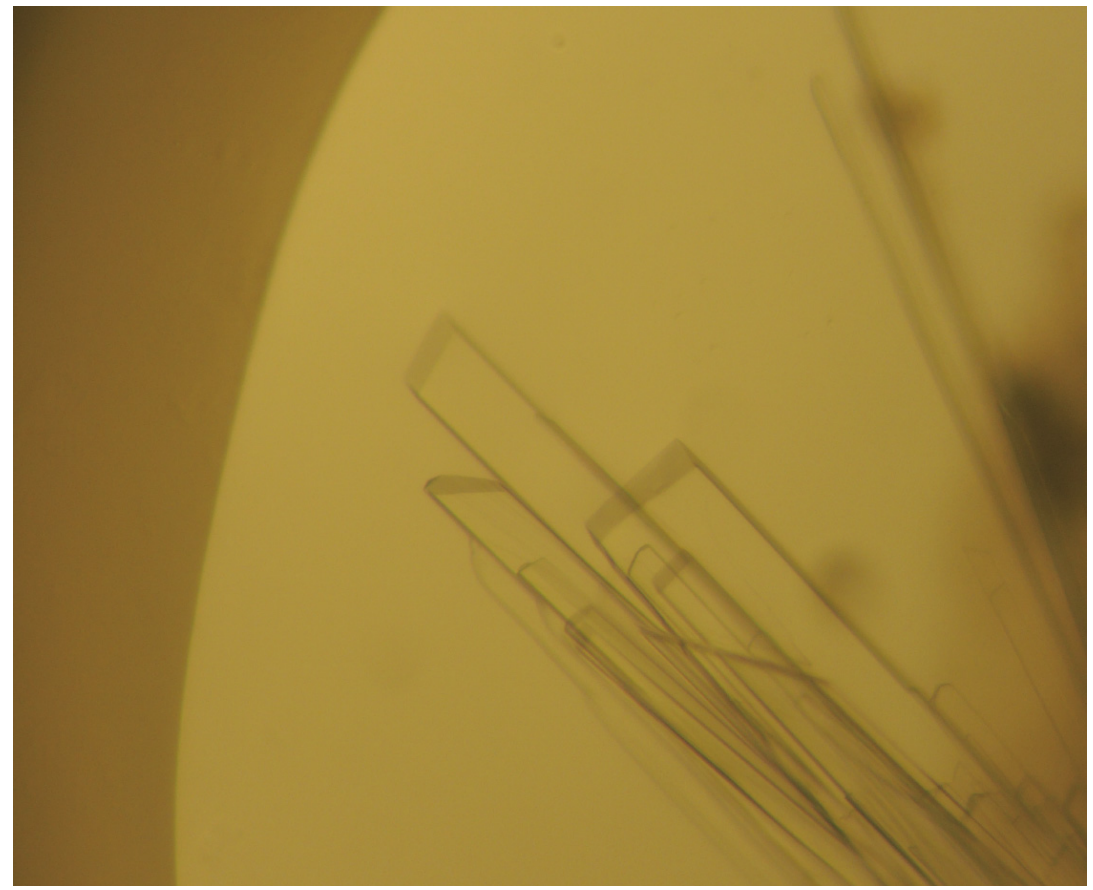

Figure 2. Results of a typical Est1DM crystals growth droplet. The crystals displayed approximately maximum size with $1.0 \times 0.3 \times 0.1 \mathrm{~mm}^{3}$.

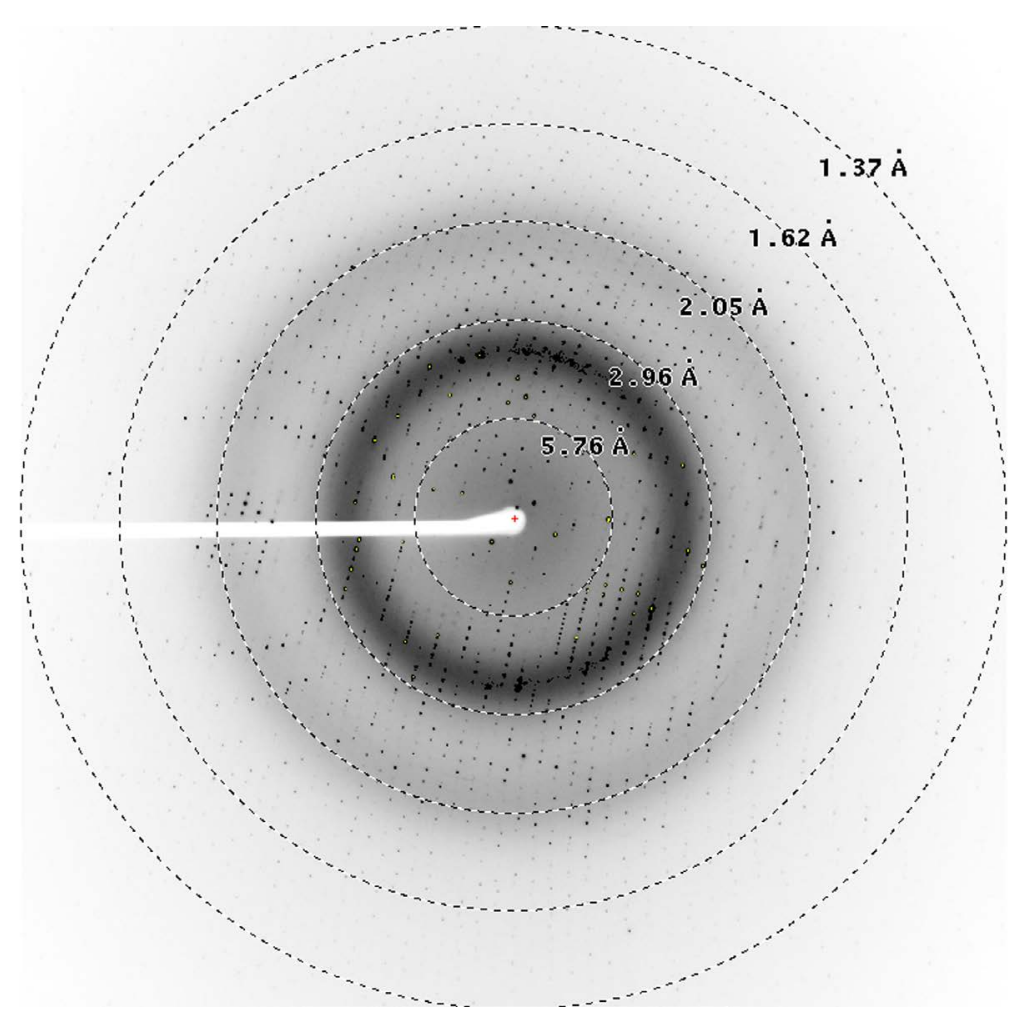

Figure 3. Diffraction image of Est1DM crystal. The circles indicate 5.76, 2.96, 2.05, 1.62 and $1.37 \AA$ resolution, respectively.

Research, Osaka University. We also thank to Prof. Fusako Kawai, for kindly giving us the est1 mutant genes. This work was supported in part by 
Table 4. Data collection and processing values for the outer shell are given in parentheses.

\begin{tabular}{|c|c|}
\hline Diffraction source & BL44XU, SPring-8 \\
\hline Wavelength $(\AA)$ & 0.9 \\
\hline Temperature (K) & 100 \\
\hline Detector & MX300HE \\
\hline Crystal-detector distance $(\mathrm{mm})$ & 190 \\
\hline Rotation range per image $\left({ }^{\circ}\right)$ & 1 \\
\hline Total rotation range $\left({ }^{\circ}\right)$ & 200 \\
\hline Exposure time per image (s) & 1 \\
\hline Space group & $C 2$ \\
\hline$a, b, c(\AA)$ & $127.2,42.1,63.2$ \\
\hline$\alpha, \beta, \gamma\left({ }^{\circ}\right)$ & $90.0,114.7,90.0$ \\
\hline Mosaicity $\left({ }^{\circ}\right)$ & 0.33 \\
\hline Resolution range $(\AA)$ & $50-1.37(1.39-1.37)$ \\
\hline Total No. of reflections & 250,545 \\
\hline No. of unique reflections & 62,727 \\
\hline Completeness (\%) & $98.3(99.7)$ \\
\hline Redundancy & $4.0(4.0)$ \\
\hline$\langle I / \sigma(I)\rangle$ & $25.3(10.1)$ \\
\hline$R_{\text {r.i.m. }}$ & $0.058(0.194)$ \\
\hline Overall $B$ factor from Wilson plot $\left(\AA^{2}\right)$ & 15.2 \\
\hline
\end{tabular}

Grants-in-Aid for Scientific Research from the Ministry of Education, Culture, Science and Technology of Japan.

\section{References}

[1] Pio, T.F. and Macedo, G.A. (2009) Cutinases: Properties and Industrial Applications. Advances in Applied Microbiology, 66, 77-95.

https://doi.org/10.1016/S0065-2164(08)00804-6

[2] Hu, X., Thumarat, U., Zhang, X., Tang, M. and Kawai, F. (2010) Diversity of Polyester-Degrading Bacteria in Compost and Molecular Analysis of a Thermoactive Esterase from Thermobifida alba AHK119. Applied Microbiology and Biotechnology, 87, 771-779. https://doi.org/10.1007/s00253-010-2555-x

[3] Dresler, K., Heuvel, J., Muller, R.J. and Deckwerl, W.D. (2006) Production of a Recombinant Polyester-Cleaving Hydrolase from Thermobifida fusca in Escherichia coli. Bioprocess and Biosystems Engineering, 29, 169-183. https://doi.org/10.1007/s00449-006-0069-9

[4] Acero, E.H., Ribitsch, D., Steinkellner, G., Gruber, K., Greimel, K., Eiteljoerg, I., Trotscha, E., Wei, R., Zimmermann, W., Zinee, M., Cavco-Paulo, A., Freddi, G., Schwab, H. and Guebitz, G. (2011) Enzymatic Surface Hydrolysis of PET: Effect of Structural Diversity on Kinetic Properties of Cutinases from Thermobifida. Macromolecules, 44, 4632-4640. https://doi.org/10.1021/ma200949p

[5] Thumarat, U., Nakamura, R., Kawabata, T., Suzuki, H. and Kawai, F. (2012) Biochemical and Genetic Analysis of a Cutinase-Type Polyesterase from a Thermo- 
philic Thermobifida alba AHK119. Applied Microbiology and Biotechnology, 95, 419-430. https://doi.org/10.1007/s00253-011-3781-6

[6] Thumarat, U., Kawabata, T., Nakajima, M., Nakajima, H., Sugiyama, A., Yazaki, K., Tada, T., Waku, T., Tanaka, N. and Kawai, F. (2015) Comparison of Genetic Structures and Biochemical Properties of Tandem Cutinase-Type Polyesterases from Thermobifida alba AHK119. Journal of Bioscience and Bioengineering, 120, 491-497. https://doi.org/10.1016/j.jbiosc.2015.03.006

[7] Kitadokoro, K., Thumarat, U., Nakamura, R., Nishimura, K., Karatani, H., Suzuki, H. and Kawai, F. (2012) Crystal Structure of Cutinase Est1 19 from Thermobida alba AHK119 that Can Degrade Modified Polyethylene Terephthalate at 1.76 A Resolution. Polymer Degradation and Stability, 97, 771-775. https://doi.org/10.1016/j.polymdegradstab.2012.02.003

[8] Roth, C., Wei, R., Oeser, T., Then, J., Föllner, C., Zimmermann, W. and Sträter, N. (2014) Structural and Functional Studies on a Thermostable Polyethylene Terephthalate Degrading Hydrolase from Thermobifida fusca. Applied Microbiology and Biotechnology, 98, 7815-7823. https://doi.org/10.1007/s00253-014-5672-0

[9] Ribitsch, D., Hromic, A., Zitzenbacher, S., Zartl, B., Gamerith, C., Pellis, A., Jungbauer, A., Łyskowski, A., Steinkellner, G., Gruber, K., Tscheliessnig, R., Herrero Acero, E. and Guebitz, G.M. (2017) Small Cause, Large Effect: Structural Characterization of Cutinases from Thermobifida cellulosilytica. Biotechnology and Bioengineering, 114, 2481-2488. https://doi.org/10.1002/bit.26372

[10] Jancarik, J. and Kim, S.H. (1991) Sparse Matrix Sampling: A Screening Method for Crystallization of Proteins. Journal of Applied Crystallography, 24, 409-411. https://doi.org/10.1107/S0021889891004430

[11] Otwinowski, Z. and Minor, W. (1997) Processing of X-Ray Diffraction Data Collected in Oscillation Mode. Methods in Enzymology, 276, 307-326. https://doi.org/10.1016/S0076-6879(97)76066-X

[12] Matthews, B.W. (1968) Solvent Content of Protein Crystals. Journal of Molecular Biology, 33, 491-497. https://doi.org/10.1016/0022-2836(68)90205-2

[13] Vagin, A. and Teplyakov, A. (2010) MOLREP. An Automated Program for Molecular Replacement. Acta Cryst, D66, 22-25. https://doi.org/10.1107/S0907444909042589

[14] Winn, M.D., Ballard, C.C., Cowtan, K.D., Dodson, E.J., Emsley, P., Evans, P.R., Keegan, R.M., Krissinel, E.B., Leslie, A.G.W., McCoy, A., McNicholas, S.J., Murshudov, G.N., Pannu, N.S., Potterton, E.A., Powell, H.R., Read, R.J., Vagin, A. and Wilson, K.S. (2011) Overview of the CCP4 Suite and Current Developments. ActaCryst, D67, 235-242. https://doi.org/10.1107/S0907444910045749

\section{Abbreviations Used}

Est1DM (cutinase est1 double mutant), PET (Polyethylene Terephthalate). 